\title{
Concomitant ablation for atrial fibrillation during septal myectomy in patients with hypertrophic obstructive cardiomyopathy
}

\author{
A Bogachev-Prokophiev", S Zheleznev, M Fomenko, A Pivkin, A Afanasiev, R Sharifulin, A Karaskov \\ From World Society of Cardiothoracic Surgeons 25th Anniversary Congress, Edinburgh \\ Edinburgh, UK. 19-22 September 2015
}

\section{Background/Introduction}

Atrial fibrillation (AF) is the most common tachyarrhythmia in patients with hypertrophic obstructive cardiomyopathy (HOCM). AF emergence associated with significant clinical deterioration in patients with HOCM, that's why maintenance of sinus rhythm is desirable. The most papers are reported results about catheter AF ablation but only paper including date about concomitant AF ablation during septal myectomy.

\section{Aims/Objectives}

Aim of the study was evaluation efficacy of concomitant AF ablation during septal myectomy in patients with HOMC.

\section{Method}

Between 2010 and 2013, 187 patients underwent of extended myectomy procedures. In 45 cases was performed concomitant AF ablation. AF was paroxysmal in $26(58 \%)$, persistent in 19 (42\%). Mean age was $52.8 \pm$ 14.2 years (range 22 to 74 years). A primary HOCM was the main indication for surgery according to $2011 \mathrm{ACCF} /$ AHA guidelines. Mean peak gradient was $90.7 \pm 24.2 \mathrm{~mm}$ $\mathrm{Hg}$, thickness of interventricular septum was $26.1 \pm$ $4.3 \mathrm{~mm}$. Mean AF duration was $17 \pm 8$ months.

\section{Results}

There were no early death. No procedure-related complications occurred with regard to ablation procedure. Complete atrioventricular block was in $2(4.0 \%)$ cases with dual-chamber pacemaker implantation. Mean time cross clamping was $61.7 \pm 26.2 \mathrm{~min}$. Peak LVOT gradient was
$14.6 \pm 5.5 \mathrm{mmHg}$. Ablation technique was maze IV procedure for all patients (RF ablation with bipolar clamp + cryo lesion for mitral and tricuspid lines). Because of atrial wall thickness (5-6 mm) applications performed 810 times at the same line. There were no pacemaker implantation due to sinus node dysfunction. All patients were discharged in stable sinus rhythm. Mean follow-up was $24 \pm 7$ months. AF freedom at 6 months was $100 \%$ (45 pts), at 1 year was $93.3 \%$ (42 pts) and at 21 months was $82.2 \%$ (37 pts).

\section{Discussion/Conclusion}

Concomitant ablation for AF during septal myectomy in patients with HOCM safe and effective procedure, and should be considered carefully in these kind patients.

Published: 16 December 2015

doi:10.1186/1749-8090-10-S1-A139

Cite this article as: Bogachev-Prokophiev et al:: Concomitant ablation for atrial fibrillation during septal myectomy in patients with hypertrophic obstructive cardiomyopathy. Journal of Cardiothoracic Surgery 2015 10(Suppl 1):A139. 